\title{
Interventions for struggling adolescent and adult readers: instructional, learner, and situational differences
}

\author{
Mary Beth Calhoon • Hollis S. Scarborough • \\ Brett Miller
}

Published online: 31 March 2013

(C) Springer Science+Business Media Dordrecht 2013

There is a pressing need to provide effective instruction for struggling adolescent and adult readers, a large and growing population whose literacy levels can be a limiting factor on educational and occupational success. Recent findings from the International Adult Literacy Survey (IALS) and the Progress in International Reading Study (PIRLS) illustrate the scope of the problem. The IALS's results indicated that $21-24 \%$ of adults read prose at the lowest level scored, indicating difficulty in making even "low-level, text-based inferences" (International Adult Literacy Survey Institute, 2011). Looking at pre-adolescents and adolescents, the picture is unfortunately similar to the adults. About $18 \%$ of US students in fourth grade (and $20 \%$ of the entire international sample-generally in the fourth grade) performed at or below the "low" benchmark on the PIRLS assessment (National Center for Educational Statistics, 2013), which corresponds to simply being able "to locate and retrieve information from different parts of the text". At eighth grade in the US, the National Assessment of Educational Progress (NAEP) data suggest continued difficulties by many students to perform above the basic level; specifically, $43 \%$ of 8 th grade students scored at or below 'basic' level (Bottoms and Timberlake, 2012), while $62 \%$ of 8th grade students with disabilities scored

The opinions and assertions presented in this article are those of the authors and do not purport to
represent those of the Eunice Kennedy Shriver National Institute of Child Health and Human
Development, the National Institutes of Health, or the US Department of Health and Human Services.

M. B. Calhoon $(\bowtie)$

Lehigh University, Bethlehem, PA, USA

e-mail: mbc310@Lehigh.EDU

\section{H. S. Scarborough}

Haskins Laboraties, New Haven, CT, USA

B. Miller

Eunice Kennedy Shriver National Institute of Child Health and Human Development,

Rockville, MD, USA 
below the 'basic' level (Levenson, 2012). Indicating that adolescents are demonstrating only partial mastery of the knowledge and skills needed to perform required school work at the eighth grade level (Bottoms and Timberlake, 2012). Unfortunately, these data illustrate that literacy needs remain unmet for substantial numbers of adolescents and adults.

To design and deliver effective instructional programs for this population, it is important to have solid evidence-based answers to some fundamental questions about literacy intervention design and delivery. In this population, do some instructional approaches yield stronger benefits than other programs? Are there demographic or skill differences among adolescent and adult students that are associated with lower attrition rates or stronger improvement? Is it fruitful to measure and examine intervention outcomes both for individuals and for learner groups? At present, unfortunately, relatively little is known about these issues due to the dearth of rigorous research studies on these topics.

In evaluating the effectiveness of remedial reading interventions, traditionally researchers compare the amount of improvement obtained by learner groups who varied on factors such as the amount or type of instruction they were provided. This analytic viewpoint is effective at describing overall gains (or lack thereof) for intervention recipients at the group-level, but because of this strength, it can obfuscate improvement (or lack thereof) that may be present for specific subgroups. Significant gains in key literacy skill development have been hard-earned for struggling adolescent and particularly adult learners (Alamprese, MacArthur, Price, \& Knight, 2011; Calhoon, 2005; Calhoon, Sandow, \& Hunter, 2010; Greenberg et al., 2011; Sabatini, Shore, Holtzman, \& Scarborough, 2011; Vaughn et al., 2010, 2011, 2012). This difficulty, to find robust responses to intervention, may not be surprising in view of the atypical educational histories of older learners and the heterogeneity of their backgrounds and skill deficits. It may be fruitful to supplement such analyses of group differences with analyses of outcomes for individual learners to enable a teasing apart of learner-by-treatment effect. A fuller picture may be provided by examining results at both the group and individual (or "person-oriented") level so as to enhance knowledge about which, and for whom, particular instructional approaches are likely to be most beneficial and how this may vary by context or learner. This information would be particularly relevant for refining interventions to address the specific needs and characteristics of older struggling readers. Consequently, the five papers composing this special issue examine their data from both group and individual level perspectives.

These five research papers and their corresponding research projects draw from theoretically motivated reading intervention studies, including three with adult learners and two with adolescent samples. Each project looked for evidence-based answers to some of the questions of interest listed earlier and examined individual differences in addition to group effects. Specifically, two papers focused on the potential bases for attrition in adult literacy education, and identifying potential means of reducing the low retention rates that are typical particularly for adult basic and secondary education populations. The remaining three papers examined reading gains by students who had longer, sustained involvement in interventions and received sufficient hours of instruction to presumably reap measurable benefits. 
Finally, two of these latter three intervention papers also sought to compare the effectiveness of alternative instructional approaches for strengthening reading skills of struggling older learners.

Greenberg, Wise, Frijters, and Morris' contribution, Persisters and nonpersisters: Identifying who stays and who leaves from adult literacy interventions, profiled three groups of adult learners: those who completed a set number of reading classes (100 h); those who withdrew halfway through the program; and those who withdrew at an earlier point. In this study, specific learner characteristics (English language status, age, some reading related skills, avoidance of reading, previous adult education experience), class assignment, and whether the learner received Women, Infants, and Children benefits all significantly predicted persistence. Additionally, English language status, gender, age, some reading related skills, and information access were the most notable characteristics that differentiated the completers and from those who withdrew from the program early.

Mellard, Fall, Krieshok, and Woods' contribution is entitled, Dispositional Factors Affecting Motivation During Learning in Adult Basic and Secondary Education Programs. Prior research indicates that about a quarter of adult students exit formal adult basic and secondary education (ABE/ASE) programs before completing one full educational level. Mellard and colleagues' retrospective study explored individual dispositional factors that are hypothesized to affect motivation during learning. The authors examined students' goals, goal-directed thinking and action from the viewpoint of hope theory (Snyder et al., 1991): Additionally, they assessed attendance behaviors, self-perceptions of competency based on affective domain attributions about external and internal obstacles to learning and employment, and demographic factors. Critically and perhaps surprisingly, learners who made an education gain in 1 year significantly differed from those who did not on dispositional or demographic variables. These findings suggest researchable questions and programmatic considerations that may lead to future innovations that improve learner persistence.

Frijters, Morris, Sevcik, and Lovett, in their article entitled, Four methods of identifying change in the context of a multiple component reading intervention for struggling middle school readers, analyzed outcome data from a study of the PHAST Reading intervention (Lovett et al., 2000). The authors characterized individual change using four methods: (a) normalization relative to age-appropriate standards; (b) the Jacobson-Truax index, a measure of statistically-reliable, pre-post change; (c) individually estimated growth rates using hierarchical linear modeling; and (d) change to a fixed criterion across multiple measures. These four change metrics were compared regarding their utility in identifying intervention outcomes. Results indicate that each method duplicated traditional group-based effect sizes, with the reliable change index and growth curve approaches showing stronger consistency and predictive power.

Calhoon and Petscher's paper, Individual and group sensitivity to remedial reading program design: Examining reading gains across three middle school reading projects, describes an investigation of group- and individual-level responses by adolescent learners, who received one of three different modalities of the same reading program, Reading Achievement Multi-Component Program (RAMP-UP; 
Calhoon, 2003). The use of latent change score analyses in combination with individual gain classifications (less than one vs. one or more years of normative growth) were used to explore effects of instructional modality, and differential sensitivity to modality. Results from both analytic approaches indicated that reading outcomes for these struggling adolescent readers were strongly related to the modality in which reading instruction had been provided. For some measures, however, the optimal modality was different for students with differing initial levels of reading proficiency. Across measures, $42-87 \%$ of students in the most effective condition, and 14-65\% of students receiving the least effective modality, met the gain criterion.

Scarborough, Sabatini, Shore, Cutting, Pugh, and Katz's contribution, Meaningful Reading Gains by Adult Literacy Learners, used within-individual gains replicated over tests (WIGROT) as the method for identifying gainers. Neither group nor individual analyses revealed differences in efficacy between the three instructional programs that were compared. The $46 \%$ of the sample who were classified as gainers had higher pretest scores than non-gainers on measures of reading and phonological awareness, and included fewer adults with a history of special education.

Returning to the questions posed earlier, the findings from the five projects yield some interesting answers, although tentative and preliminary ones.

In this population, do some instructional approaches bring about stronger benefits than other programs? Consistent with most previous intervention studies with adult literacy learners, Scarborough et al.'s findings yielded no strong evidence for differential effectiveness of different reading curricula. However, Calhoon and Petscher found compelling indications that the level of improvement by their adolescent sample and the percentages of students classified as gainers, were influenced by the way that elements of how a common curriculum were organized and sequenced during instruction. This suggests that future research might benefit from examining the organizational aspects of instruction, as investigated here.

Are there demographic or skill differences among adolescent and adult students that are associated with lower attrition or stronger improvement? With regard to skill improvement, outcomes in three of the studies were associated with differences in the initial reading skill level of older learners (Calhoon and Petscher, 2013; Greenberg et al., 2012; Scarborough et al., 2012). Additionally, two of the adults studies found differences associated in demographics characteristics of students who maintained enrollment and those who dropped out (Greenberg et al., 2012; Mellard et al., 2012).

Is it fruitful to measure and examine intervention outcomes both for individuals and for learner groups? Taken together, the findings of these five studies indicate that supplementing group level results with analyses of individual data can be useful in evaluating the practical efficacy of literacy interventions. By comparing persisters with dropouts, or gainers with non-gainers, researchers can more effectively focus on the complex factors that contribute to effective instruction for this diverse population.

The studies reported here provide encouraging information towards the advancement of reading programs for older struggling readers. There is a critical need to fully understand how these older students develop reading skills and how the environmental factors influence their success in learning to read at these age levels. Investigating gains on a group and individual level provides valuable 
knowledge about which and for whom particular instructional approaches are effective, and how specific instructional environmental factors contribute best to obtaining reading skills. These data are important, given the current dearth of information regarding how best to improve our understanding of the learning trajectories of individuals throughout the lifespan who have struggled and not acquired normative literacy skills. For this reason, these literacy projects which looked at results and indicators of success from both a group and individual level provide a unique and informative perspective.

\section{References}

Alamprese, J., MacArthur, C., Price, C., \& Knight, D. (2011). Effects of a structured decoding curriculum on adult literacy learners' reading development. Journal of Research on Education Effectiveness, $4(2), 154-172$.

Bottoms, G., \& Timberlake, A. (2012). Improved middle grades schools for improved high school readiness: Ten best practices in the middle grades southern regional education board. http:// www.sreb.org.

Calhoon, M. B. (2003). Reading achievement multi-component program (RAMP-UP). Unpublished adolescent remedial reading program.

Calhoon, M. B. (2005). Effects of a peer-mediated phonological skill and reading comprehension program on reading skill acquisition of middle school students with reading disabilities. Journal of Learning Disabilities, 38, 424-433.

Calhoon, M. B., \& Prescher, Y. (2013). Individual and group sensitivity to remedial reading program design: Examining reading gains across three middle school reading projects. Reading and Writing: An Interdisciplinary Journal, 1-28.

Calhoon, M. B., Sandow, A., \& Hunter, V. (2010). Re-organizing the instructional reading components: Could there be a better way to modality remedial reading programs to maximize middle school students with reading disabilities' response to treatment? Annals of Dyslexia, 60, 57-85.

Greenberg, D. Wise, J., Frijters, J., \& Morris, R. (2012). Persisters and nonpersisters: Identifying the characteristics of who stays and who leaves from adult literacy interventions. Reading and Writing: An Interdisciplinary Journal. doi:10.1007/s11145-012-9401-8.

Greenberg, D., Wise, J., Morris, R., Fredrick, L., Rodrigo, V., Nanda, Al, et al. (2011). A randomizedcontrol study of instructional approaches for struggling adult readers. Journal of Research on Education Effectiveness, 42(2), 101-117.

International Adult Literacy Survey Institute. (2011). Retrieved from the website: http://www.statcan.gc. ca/pub/89-588-x/4152887-eng.htm on March 3, 2013.

Levenson, N. (2012). Boosting the quality and efficiency of special education. Thomas Fordham Institute, http://www.edexcellence.net.

Lovett, M. W., Lacerenza, L., Borden, S. L., Frijters, J. C., Steinbach, K. A., \& De Palma, M. (2000). Components of effects remediation for developmental reading disabilities: Combining phonological and strategy-based instruction to improve outcomes. Journal of Educational Psycholody, 92(2), 263-283.

Mellard, D. F., Krieshok, T., Fall, E., \& Woods, K. (2012). Dispositional factors affecting motivation during learning in adult basic and secondary education programs. Reading and Writing: An Interdisciplinary Journal. doi:10.1007/s11145-012-9413-4.

National Center for Education Statistics. (2013). Retrieved from website: http://nces.ed.gov/surveys/pirls/ pirls2011.asp. 5 March 2013.

Sabatini, J., Shore, J., Holtzman, S., \& Scarborough, H. (2011). Relative effectiveness of reading intervention programs for adults with low literacy. Journal of Research on Education Effectiveness, 2(2), 118-133. 
Scarborough, H., Sabatini. J. P., Shore, J., Cutting, L. E., Pugh, K., \& Katz, L. (2012). Meaningful reading gains by adult literacy learners. Reading and Writing: An Interdisciplinary Journal. doi:10.1007/ s11145-012-9385-4.

Snyder, C. R., Harris, C., Anderson, J. R., Holleran, S. A., Irving, L. M., Sigmon, S. T., Harney, P. (1991). The will and the ways: Development and validation of an individual-differences measure of hope. Journal of Personality and Social Psychology, 60(4), 570-585.

Vaughn, S., Crinio, P. T., Wanzek, J., Wexler, J., Fletcher, J. M., Denton, C. D., et al. (2010). Response to intervention for middle school struggling readers: Effects of a primary and secondary intervention. School Psychology Review, 31, 2-21.

Vaughn, S., Wexler, J., Leroux, A., Roberts, G., Denton, C., Barth, A., \& Fletcher, J. (2012). Effects of intensive reading intervention for eighth-grade students with persistently inadequate response to intervention. Journal of Learning Disabilities, 45(6), 515-525. doi:10.1177/0022219411402692.

Vaughn, S., Wexler, J., Roberts, G., Bart, A., Cirino, P. T., Romain, M. A., Francia, D., Fletcher, J., \& Denton, C. A. (2011). Effect of individualized and standardized interventions on middles school students with reading disabilities. Exceptional Children, 77(4), 391-407. 